\title{
Renoprotective Effects of Oral Magnesium Supplementation among Hypomagnesemic Type 2 Diabetes Mellitus Nephropathy
}

\author{
Authors \\ Sagnika Tripathy, Butungeshwar Pradhan*, Tejeshwar Reddy P \\ Department of Medicine, VIMSAR, Burla, Sambalpur, Odisha, India \\ *Corresponding Author \\ Butungeshwar Pradhan \\ Email: butungeshwar@gmail.com, Mobile No.: 9437243697
}

\begin{abstract}
Background: Insulin resistance or deficiency and hyperglycemic osmotic diuresis increase urinary loss of magnesium. Both intracellular and extracellular magnesium deficiency may lead to early progression of diabetic nephropathy to end stage renal disease (ESRD). Benefit of oral magnesium supplementation on metabolic profiles of diabetes has been reported in some studies. Hence, the present study was undertaken to know, whether oral magnesium supplementation in hypomagnesemic T2DM nephropathy decreases proteinuria and delay the progression to ESRD.

Methods: Twenty four hour total urinary protein measurement and creatinine clearance measured by Cocroft Gault formula was done at baseline. Magnesium Oxide 400mg twice daily was given orally to 39 patients and 37 were taken as control. Twenty four hour total urinary protein, serum magnesium and creatinine clearance was repeated at $\geq 3$ month interval at least 3 times during the study period of 24 months. All patients were received standard treatment for confounding conditions and glycemic control. Data were collected and analysed and $p$ value of $<0.05$ was considered significant.

Results: T2DM patients with proteinuria who received oral magnesium had normalization of their serum magnesium levels and had declined proteinuria and improvement in GFR, in comparison to control group had further decline in serum magnesium levels and progression of proteinuria and faster deterioration of GFR.

Conclusions: Oral magnesium supplementation corrects hypomagnesaemia in patients with T2DM and decreases proteinuria and delay the progression to ESRD.
\end{abstract}

Keywords: Hypomagnesaemia, Oral Magnesium, Proteinuria, Nephropathy, T2DM.

\section{Introduction}

Magnesium (Mg) is the fourth most abundant mineral present in the human body and the second intracellular cation in the living cell after potassium. Most Mg in human body is intracellular (99\%) and only $1 \%$ is in extracellular fluid. Preclinical hypomagnesemia is considered with serum $\mathrm{Mg}$ level of $\leq 0.75 \mathrm{mmol} / \mathrm{L}$ or $1.8 \mathrm{mg} / \mathrm{dl}$ and frank hypomagnesemia with $\leq 0.61 \mathrm{mmol} / \mathrm{L}$ or $1.5 \mathrm{mg} / \mathrm{dl}$, indicative of systemic $\mathrm{Mg}$ deficit. ${ }^{1}$ The link between $\mathrm{Mg}$ deficiency and type 2 diabetes mellitus (T2DM) is well known. T2DM is frequently associated with both intracellular and extracellular $\mathrm{Mg}$ depletion. At the cellular level cytosolic free $\mathrm{Mg}$ levels are 
consistently reduced in subjects with T2DM, when compared to non-diabetics. An impairment of cellular $\mathrm{Mg}$ uptake mechanism and a decrease in cellular ATP level may contribute at least in part to explain the decreased in cellular $\mathrm{Mg}$ content observed in diabetic condition. ${ }^{2}$ Magnesium deficit as a possible unifying mechanism of conditions associated to insulin resistance including T2DM, metabolic syndrome and hypertension.

Hypomagnesemia has been related to hypertension, atherogenic dyslidimia, impaired clotting, increased inflammatory burden (increased C-RP), oxidative stress, carotid wall thickness, endothelial dysfunction and coronary artery disease (CAD). ${ }^{3}$ Magnesium deficiency could precede and cause post-receptorial resistance of insulin action and alter the glucose metabolism. ${ }^{4}$ The incidence of hypomagnesaemia in different studies varies from $13.5 \%$ to $47.7 \%$ in T2DM patients. ${ }^{5}$ There is high prevalence hypomagnesemia in subjects with T2DM, especially in poorly controlled glycemic profile with longer duration of the disease and with presence of micro or macro vascular chronic complications. ${ }^{6}$ Insulin enhances $\mathrm{Mg}$ reabsorption at the thick ascending limb (TAL) and distal convoluted tubule (DCT) of renal tubules. ${ }^{7}$ The increased frequency of hypomagnesemia in T2DM is presumably multi factorial. Insulin resistance or deficiency may exacerbate renal $\mathrm{Mg}$ wasting and hyperglycemia per se induce glycosuria causes higher osmotic urinary excretion of $\mathrm{Mg}$ and recurrent metabolic acidosis with diabetic ketoacidosis and hypoalbuminimic state decreases Mg binding. ${ }^{8}$

Hypomagnesemia has been implicated in T2DM and its complications, i.e. nephropathy, retinopathy and neuropathy etc. In a recent study it was found that T2DM with hypomagnesemic nephropathy had 2.12 fold increased risk for progression to ESRD in 23 months in comparison to hypomagnesemic nondiabetic nephropathy in 44 months, indicating hypomagnesemia is a novel predictor of progression to ESRD in T2DM nephropathy. ${ }^{9}$ Lower magnesium levels associated with faster deterioration of renal function rate in T2DM patients. ${ }^{10}$ In T2DM patients with nephropathy in both microalbuminuria and overt proteinuria states serum ionized $\mathrm{Mg}$ was found to be decreased.11 Clinical evidence of $\mathrm{Mg}$ supplementation on metabolic profiles of diabetic subjects are controversial, benefits have been found in many but not in all studies. ${ }^{12}$ Magnesium supplementation may improve fasting and postprandial states and improves the insulin mediated glucose uptake and parallel increase in plasma and erythrocyte $\mathrm{Mg}$ concentration and progressive increase in insulin sensitivity. ${ }^{13}$ Oral $\mathrm{Mg}$ supplementation restore altered endothelial function in elderly diabetic subjects. ${ }^{14}$ Hence , this study was done to know the effects of oral $\mathrm{Mg}$ supplementation whether it normalizes serum $\mathrm{Mg}$ levels, improve the progression of diabetic microalbuminuria, clinical proteinuria and renal function.

\section{Methods}

This was a prospective single centre, open label comparative, observational study conducted between July 2013 to December 2015 at VIMSARM Burla, Odisha, India among 86 T2DM patients who were attending the department of medicine and nephrology selected for the study, with microalbuminuria or proteinuria of $\geq 0.5 \mathrm{gm} / 24$ hrs or with serum creatinine of $\geq 2 \mathrm{mg} / \mathrm{dl}$ and features of chronic kidney disease (CKD) on ultrasonography (USG) grading of I,II,III,IV and V stages with serum magnesium level $<1.8 \mathrm{mg} / \mathrm{dl}$ estimated by Enzymatic end point method. Patients with stage V CKD (ESRD), chronic diarrhoea, pancreatitis, chronic alcoholism and chronic diuretic use, on $\mathrm{Mg}$ containing antacids, laxatives and other nephrotoxic drugs use and other endocrine disorders were excluded from the study. After approval of local ethical committee (VIREC Redg.No.IEC/IRB25/3) after obtaining patient's consent magnesium oxide $400 \mathrm{mg}$ twice daily was given orally alternatively to 39 hypomagnesemic T2DM patients and 37 patients were taken as control group. Baseline serum Mg, 24 hours total protein excretion and creatinine clearance by Cocroft Gault formula was done at least $\geq 3$ months intervals three times in 


\section{JMSCR Vol||07||Issue||04||Page 511-516||April}

both group in follow up period and last was done at the end of 24 months of study period. All the patients received standard treatment for confounding conditions as needed i.e. glycemic control with diet, oral antidiabetic drugs (OADs), insulin and controls of blood pressure was must with a ACEI/ARB monotherapy and addition of other appropriate antihypertensive drugs when necessary. Data were collected and analysed and $p$ value was calculated by paired ' $t$ 'test and $p$ value of $<0.05$ was considered statistically significant.

\section{Results}

Age and Sex: After drop out of 10 cases, total 76 cases completed in the study period of 24 months. Thirtyone hypomagnesemic nephropathy were between age group of $41-50(40 \%)$ and they were $18(23.68 \%)$ and $13(17.1 \%)$ male and female respectively. In age group of 50-60 years 36 $(47.36 \%)$ cases and they were $19(42.36 \%)$ and $17(22.36 \%)$ male and females respectively. Nine $(11.84 \%)$ were $>60$ years age and they were 5 male and 4 females. Majority were between 40-60 years of age.

Duration of Diabetes: Duration of diabetes was less than 5 years in $24(31.57 \%)$ of which $11(14.42 \%)$ were males and $13(17.1 \%)$ were females. Thirty eight $(50 \%)$ patients had history of diabetes for 6-10 years and they were 22 (28-.94\%) males and $16(21.05 \%)$ females. Fourteen patients had $>10$ years duration of diabetes and they were 9 $(11.84 \%)$ males and $5(6.57 \%)$ females.

\section{On Comparison of Serum Mg Levels from} Baseline to Last Visit: - An average serum $\mathrm{Mg}$ level at baseline in trial group was $1.38 \mathrm{mg} / \mathrm{dl}$ and at last visit it was $2.22 \mathrm{mg} / \mathrm{dl}$ and there was an increment of $0.84 \mathrm{mg} / \mathrm{dl}$. In control group average baseline serum $\mathrm{Mg}$ level was $1.44 \mathrm{mg} / \mathrm{dl}$ and at last visit it was $1.26 \mathrm{mg} / \mathrm{dl}$ and there was $0.18 \mathrm{mg} / \mathrm{dl}$ decline in serum Mg. $(\mathrm{p}<0.05)$. (Figure 1$)$.

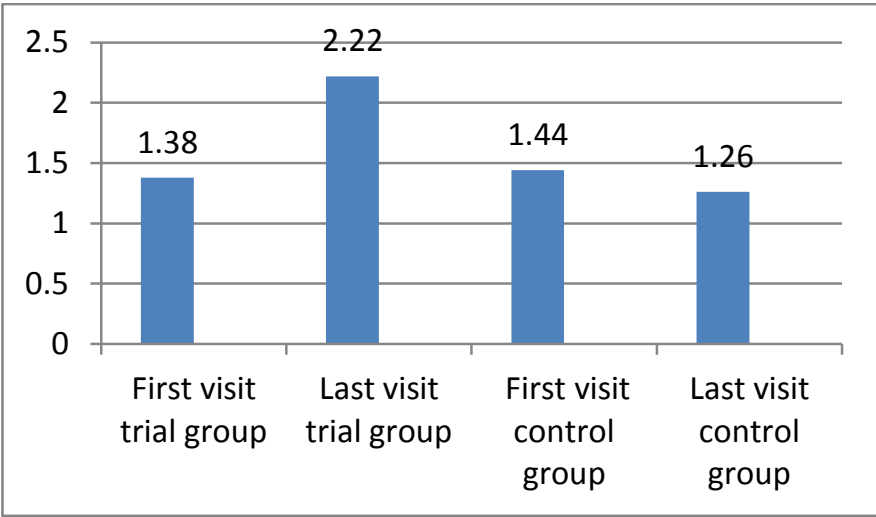

Figure 1 Comparison of Serum $\mathrm{Mg}$ evels (mg/dl) on First Visit \& Last Visit in Trial Group $(n=39)$ \& Control Group ( $\mathrm{n}=37$ ).

\section{Comparison of 24 Hours Total Protein Excretion}

Baseline average proteinuria in trial group was $1363 \mathrm{mg} / \mathrm{dl}$ in males and $1413 \mathrm{mg} / \mathrm{dl}$ in females. Average baseline proteinuria was $1378 \mathrm{mg} / \mathrm{dl}$ in both group and at last visit it was $1042 \mathrm{mg} / \mathrm{dl}$ and $1065 \mathrm{mg} / \mathrm{dl}$ in males and females respectively and an average decrease of $1006 \mathrm{mg} / \mathrm{dl}$ in both groups. There was significant decreased in proteinuria by $24 \%$ and $25 \%$ in males and females respectively with an average decreased of $315 \mathrm{mg} / \mathrm{dl}$ in trial group. Baseline proteinuria in control group was $1346 \mathrm{mg} / \mathrm{dl}$ and $1179 \mathrm{mg} / \mathrm{dl}$ in males and females respectively (average of $1261 \mathrm{mg} / \mathrm{dl}$ ) and at last visit it was $1688 \mathrm{mg} / \mathrm{dl}$ and $1474 \mathrm{mg} / \mathrm{dl}$ respectively in males and females (average of $1588 \mathrm{mg} / \mathrm{dl}$ ) suggesting progression of proteinuria by $25.4 \%$ and $25.02 \%$ in males and females respectively and there was an average increased of $327 \mathrm{mg} / \mathrm{dl}$. ( $\mathrm{p}<0.05$ ). (Figure 2).

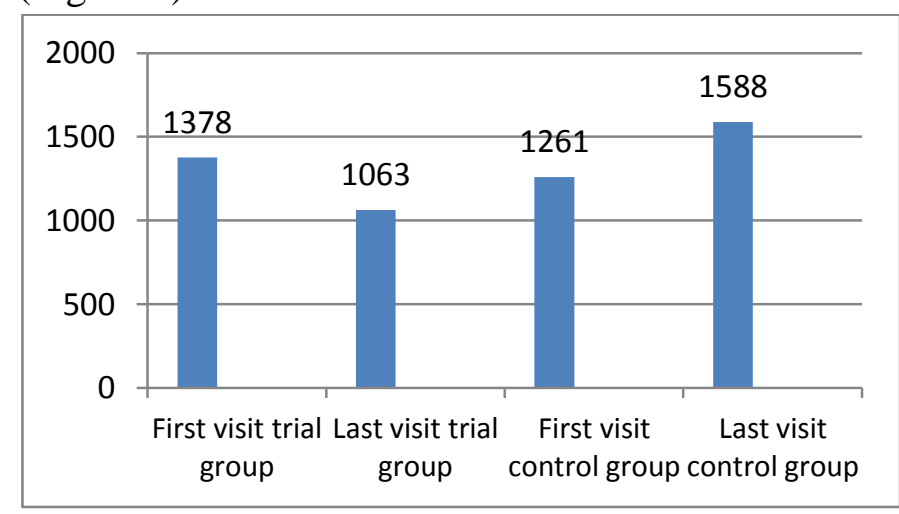

Figure 2. Comparison of Average $24 \mathrm{Hrs}$ Proteinuria Levels $(\mathrm{mg} / \mathrm{dl})$ at First Visit and Last Visit in Trial Group $(\mathrm{n}=39)$ and Control Group $(\mathrm{n}=37)$. 
Comparison of Average Creatinine Clearance or Glomerular Filtration Rate (GFR)

Baseline GFR in trial group was $45.3 \mathrm{ml} / \mathrm{min}$ and $43.2 \mathrm{ml} / \mathrm{min}$ in male and female respectively (average of $44.7 \mathrm{ml} / \mathrm{min}$ ) and at last visit it was 39 $\mathrm{ml} / \mathrm{min}$ and $37.6 \mathrm{ml} / \mathrm{min}$ in males and female respectively (average of $38.2 \mathrm{ml} / \mathrm{min}$ ) and there was decline GFR of $14 \%$ and $13 \%$ in males and females respectively( average decline of $6.5 \mathrm{ml} / \mathrm{min}$ ). In control group baseline GFR was $49 \mathrm{ml} / \mathrm{min}$ and $46 \mathrm{ml} / \mathrm{min}$ in males and females respectively (average of $47.9 \mathrm{ml} / \mathrm{min}$ ) and at last visit it was $37.7 \mathrm{ml} / \mathrm{min}$ and $37.3 \mathrm{ml} / \mathrm{min}$ in males and females respectively (average of $37.5 \mathrm{ml} / \mathrm{min}$ ) and there was decline of GFR of $23 \%$ and $19 \%$ in males and females respectively (average decline of $10.4 \mathrm{ml} / \mathrm{min})$. $(\mathrm{P}<0.05)$. (Figure 3$)$.

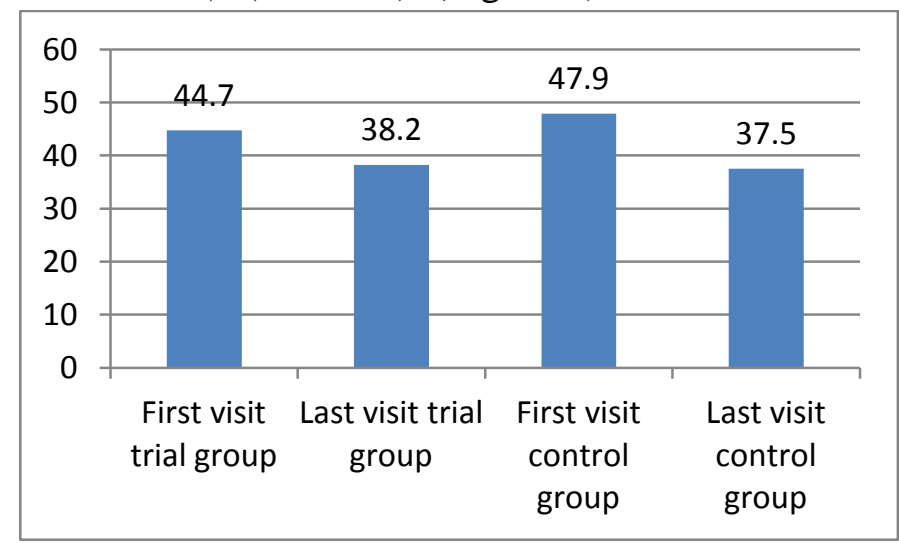

Figure 3 Comparison of Creatinine Clearance or GFR ( $\mathrm{ml} / \mathrm{min})$ at First Visit \& Last Visit in Trial Group $(n=39) \&$ Control Group (n=37).

\section{Discussion}

In this study $\mathrm{Mg}$ supplementation to $\mathrm{T} 2 \mathrm{DM}$ hypomagnesemic nephropathy decreased proteinuria and slowed the progressive deterioration of GFR in comparison to control hypomagnesemic diabetic nephropathy patients with faster deterioration of GFR and progression of proteinuria and further decreased in concentration of serum magnesium levels. There was no significant difference between the age and sexes. In type 1 diabetes with albuminuria GFR decline about $1,2 \mathrm{ml} / \mathrm{min} / \mathrm{month}$ without therapeutic intervention and in T2DM decline in GFR was more variable and may decline by $0.5 \mathrm{ml} / \mathrm{min} / \mathrm{month}$ and in some patient it may remain stable for long period. ${ }^{15}$ The clinical evidence of clear effects of $\mathrm{Mg}$ supplementation on the metabolic profiles of diabetic subjects are controversial, as benefits were found in many studies but not in all clinical trials may be due to the presence of many confounding factors has not been considered or may be related to small number of subjects and using different $\mathrm{Mg}$ doses or salts. ${ }^{2}$ In a recent clinical randomized, double blind placebo controlled trial of oral $\mathrm{Mg}$ supplementation to prediabetes with frank hypomagnesemia, there was decreased in C-reactive protein (CRP) levels along with beneficial effects on fasting and postprandial glucose levels and insulin sensitivity was found. ${ }^{16{ }^{17}}$ Magnesium supplementation in diabetic subjects with hypomagnesemia corrects the intracellular free $\mathrm{Mg}$ levels, improves insulin sensitivity and may protect against diabetic complications. The positive effects of high intake of $\mathrm{Mg}$ on systemic inflammation and insulin resistance may help to explain at least some of its favourable effects. ${ }^{2}$ Insulin deficiency or resistance can affect the tubular absorption of $\mathrm{Mg}$ leading to hypomagnesemia in T2DM subjects. ${ }^{18}$ Finally a vicious circle formed by mutual influence between insulin resistance and hypomagnesemia resulting in aggravation of insulin resistance which can increase the risk of microalbuminuria and proteinuria both as a consequence of glomerular damage and causes further damage since it can lead to inflammation and fibrosis in the renal tubules and loss of number of functional nephrons..$^{19}{ }_{20}$

\section{Conclusions}

A low $\mathrm{Mg}$ intake in the state of increased urinary $\mathrm{Mg}$ loss with proteinuria in diabetic nephropathy due to insulin resistance or insulin deficiency, leads to hypomagnesaemia and faster progression to ESRD. Benefits of $\mathrm{Mg}$ supplementation in diabetic nephropathy have been found in our study. T2DM patients with proteinuria and renal dysfunction need intensive multifaceted treatment strategies for all known modifiable risk factors including $\mathrm{Mg}$ supplementation to reduce cardiovascular and microvascular complications and extend life 
expectancy. There is scarcity of reports on $\mathrm{Mg}$ supplementation in diabetic nephropathy. Future large prospective, multi centre randomized, double blind placebo controlled clinical studies are needed to support the potential role of oral $\mathrm{Mg}$ supplementation in diabetes mellitus and its chronic complications.

\section{Acknowledgement}

We are very much thankful to all the participant patients in this study for their kind consent and timely follow up attendance. We also vote thanks to all the staffs of Regional diagnostic centre VIMSAR, Burla for their cooperation in the different investigations done for the study.

\section{Declarations}

Funding: NIL.

Conflict of interest: NONE.

Ethical Approval: VIREC Redg.No.IEC/IRB-25/3

\section{References}

1. Barbagallo M, Di Bella G, Brucato V, D Angil, Domiano P et al. Serum ionized magnesium in diabetic older person.Metabolism.2014;63:502-509.

2. Barbagallo M, Dominguez LJ, Resnick LM. Magnesium metabolism in hypertension and type 2 diabetes mellitus, Am J Ther .2007; 13:375-285.

3. Laurant $P$, Berthelot A. Influence of endothelium on $\mathrm{Mg}^{2+}$ induced relaxation in nor-adrenaline contracted aorta from DOCA- salt hypertensive Rats. European J Pharmacology.1994; 258-167.

4. Barbagallo M, Dominguez LJ, Galloto A, Ferlisi A, Cani C et al. Role of magnesium in insulin action, diabetes and cardiometabolic syndrome X. Mol Aspects Med.2003;24:39-52.

5. Pramod P Rao, Mohamed Ghouse Shariff. Serum magnesium levels in type 2 diabetic patients with microalbuminuria and normoalbuminuria. Int $\mathbf{J}$ Seincetific study. July 2015; 3:4. P-11-15.
6. Mario Barbagallo, Liga J, Dominguez. Magnesium and type 2 diabetes. An Update. Diabetes and Clin Res.2015 Jan; 22:1-5.

7. Madon B, Siga E, Chabardes D, Firsov D, Roenel N, De Rouffigbac C. Insulin stimulates $\mathrm{NA}+, \mathrm{Cl}-, \mathrm{Ca}++$ and $\mathrm{Mg}++$ transport in TAL of mouse nephron : Cross potentiation with AVP Am J Physiol.1993;F361-369.

8. Barbagallo M, Dominguez LJ. Magnesium metabolism in type 2 diabetes mellitus, metabolic syndrome and insulin resistance. Arch Biochem Biophys.2007; 458:40.p-7.

9. Sakaguichi Y, Shoji T, Hayashi T, Sujuki A, Shimizu M, Mitsumoto K, Tsubakihara Y. Hypomagnesaemia in type 2 diabetes mellitus nephropathy; a novel predictor of end stage renal disease. Diabetes Care. July2012; 1591-1597.

10. Pham PC, Pham SV, Miller JM, Pham PT. Hypomagnesaemia in patients with type 2 diabetes mellitus. Cli J Res .2015 Jan; 22:21-5.

11. Corsenello A, Lentile R, Bueni M, Cucinatto D, Mouro VN, Macaione S, Carcia F. Serum ionized magnesium levels in type 2 diabetes mellitus patients with microalbuminuria and clinical proteinuria. Am J Nephrol.200; 20:187-192.

12. De Valk HW, Verkaaik R, Von Rjn HJ, Greerdink RA, Struyvenberg A. Oral magnesium supplementation in insulin requiring type 2 diabetes patients. Diabet Med .1998; 15:503-507.

13. Paolisso G, Barbagallo M. Hypertension, diabetes mellitus and insulin resistance; the role of intracellular magnesium. Am J Hypertsns.1997; 10:346-355.

14. Barbagallo M, Dominguez LJ, Gallato A, Pineo A, Belvedere M. Oral magnesium supplementation improves vascular function in elderly diabetes patients. Magnesium research official organ of the international society for the development of research on magnesium.2010; 23:131-137. 
15. Rodriguez Moran M, Guerrero Romero F. Low serum magnesium levels and foot ulcer in subjects with type 2 diabetes. Arch Med Res.32:84:300-303.

16. Simentel Mendia E, Rodriguez Moran M, Guerrero Romero F. Oral magnesium supplementation decreased C-reactive protein level in subjects with prediabetes and hypomagnesaemia a clinical randomized double blind placebo controlled trial. Arch of Med Research.2014; 45:325-330.

17. Rodriguez Moran, Guerrero-Romero F. Oral magnesium improves insulin sensitivity and metabolic control in type 2 diabetes subjects, a randomized double blind control trial. Diabetes Care.2003; 26:1147-1152.

18. Hsu CC, Chang HY, Huang MC, Hwang SJ, Yang YC, Tai TY et al. Association between insulin resistance and development of microalbuminuria in type 2 diabetes. A prospective cohort study. Diabetes Care.2011; 34:982-987.

19. Gall MA, Nielsen FS, Smidt UM, Parving $\mathrm{HH}$. The course of kidney function in type 2 non-insulin dependent diabetes mellitus patients with diabetic neuropathy. Diabetologia.1999; 36:1071-1078.

20. Gaede P, Oellgaard J, Catstensen B, Rossiq $\mathrm{P}$, Lund Andersen H, Parving HH, Pedersen O. Diabetologia. Aug 16(up head in print).Abstract. 